\title{
Do Macroeconomic Announcements Move Inflation Forecasts?
}

\author{
Marlene Amstad and Andreas M. Fischer
}

\begin{abstract}
This paper presents an empirical strategy that bridges the gap between event studies and macroeconomic forecasts based on common-factor models. Event studies examine the response of financial variables to a market-sensitive "surprise" component using a narrow event window. The authors argue that these features—narrow event window and surprise component—can be easily embedded in common-factor models that study the real-time impact of macroeconomic announcements on key policy variables such as inflation or gross domestic product growth. Demonstrative applications are provided for Swiss inflation that show that (i) the communication of monetary policy announcements generates an asymmetric response for inflation forecasts, (ii) the pass-through effect of import price releases on inflation forecasts is weak, and (iii) macroeconomic releases of real and nominal variables generate nonsynchronized effects for inflation forecasts. (JEL E37, E52, E58)
\end{abstract}

Federal Reserve Bank of St. Louis Review, September/October 2009, 91(5, Part 2), pp. 507-18.

4

$\mathrm{n}$ attractive feature of diffusion indices is their ability to embed timely information from macroeconomic releases. Studies using common-factor procedures by Forni et al. (2000) and Stock and Watson (2002) show that updated forecasts have lower forecast errors because additional observations from macroeconomic releases are included in a growing panel. Evans (2005) and Giannone, Reichlin, and Small (2008) develop a procedure that updates quarterly U.S. gross domestic product (GDP) nowcasts (i.e., forecasts for the current quarter) as information from staggered macroeconomic releases arrives. Similarly, Altissimo et al. (2007) argue that integration of early information at a monthly frequency improves quarterly GDP nowcasts for the euro area. At a higher frequency, Amstad and Fischer (2009a) show that weekly updates enhance the forecast accuracy for monthly Swiss inflation. These studies argue that sequentially updating the forecast on incoming macroeconomic information is informative for analysts monitoring nominal and real activity.

A drawback of diffusion indices is that they are statistical models without economic structure. A naive method of uncovering the driving forces behind forecasts from common-factor models compares the forecasting performance between included and excluded variable blocks in the panel. Forni et al. (2001) use this method to show that financial variables are important for inflation forecasts. Analogous to the naive method, the impact of macroeconomic announcements on indices can be interpreted using an event study framework. The "impact effect" is defined as the difference between the forecast conditional on

\footnotetext{
Marlene Amstad was a visiting senior economist at the Federal Reserve Bank of New York when this paper was written; she is the head of financial market analysis at the Swiss National Bank. Andreas M. Fischer is an economic adviser at the Swiss National Bank, research fellow at the Centre for Economic Policy Research (London), and research associate at the Globalization and Monetary Policy Institute (Federal Reserve Bank of Dallas). The authors thank Michael Dueker, Domenico Giannone, Simon Potter, Lucrezia Reichlin, and Robert Rich for valuable discussions. Tobias Grassli provided valuable assistance in data support.

(C) 2009, The Federal Reserve Bank of St. Louis. The views expressed in this article are those of the author(s) and do not necessarily reflect the views of the Federal Reserve System, the Board of Governors, the regional Federal Reserve Banks, or the Swiss National Bank. Articles may be reprinted, reproduced, published, distributed, displayed, and transmitted in their entirety if copyright notice, author name(s), and full citation are included. Abstracts, synopses, and other derivative works may be made only with prior written permission of the Federal Reserve Bank of St. Louis.
} 
information after the macroeconomic release and the forecast conditional on information before the macroeconomic release. Event studies, which measure the impact of an economic event on a variable of interest, have a rich tradition in macroeconomics and finance. ${ }^{1}$ These studies often work with a narrow event window to capture the financial market response to an announcement surprise component. In a similar manner, forecast innovations from a common-factor model centered on a macroeconomic release with a narrow and fixed event window lend themselves readily to an event study interpretation.

Our objective here is to bridge the gap between event studies examining the impact of macro announcements for financial variables and conventional macro models embodying a broad range of macroeconomic information. More specifically, we want to know whether macroeconomic announcement effects for a narrow event window have a strong impact on the inflation forecast. It is no surprise that wide event windows-say, more than one month-generate large forecast revisions, but it is unclear whether the same is true for narrow event windows of one day. The proposed identification procedure relies on generating forecast innovations for the macroeconomic series based on panels updated on a daily basis using the dynamic common-factor procedure developed by Forni et al. (2000). The one-day event window defined by the postrelease and prerelease dates of macroeconomic releases allows interpretation of the announcement's impact on inflation forecasts.

The advantages of our procedure over previous event studies that analyze announcement effects are twofold. The first concerns the information breadth captured in the anticipated component of the event. The pre-event forecast from the common-factor model is projected on a data-rich environment, whereas previous event studies rely on information from simple ordinary least squares regressions and survey data or have no prior information. The second advantage is that announce-

1 See MacKinlay (1997) for a survey of the literature and empirical tests. ment effects can be analyzed for a wide range of variables. They include all the variables in the panel. Previous event studies focused exclusively on financial variables to capture the announcement effect.

The empirical analysis considers three applications of the event study procedure to Swiss inflation. The case studies are demonstrative, reflecting the view that the proposed framework has broad applications. The first exercise examines the size of forecast innovations on days when the Swiss National Bank (SNB) announces its target range for its policy interest rate. Numerous studies surveyed by Blinder et al. (2008) have examined the response of financial markets to central bank communications but not whether central bank communications can have an impact on the inflation forecast through the market's response and subsequent effect on financial variables. We want to know whether the financial variables in the panel respond to SNB announcements and, in turn, influence the inflation forecast. The second exercise investigates whether forecast errors generated by the release of real and nominal macroeconomic variables influence inflation forecasts in a synchronous manner. With this information we want to understand how forecasts behave over the cycle. The third exercise analyzes whether inflation forecasts respond to import price releases. We argue that the forecast innovation centered on import price releases can be interpreted as an alternative measure of the pass through from import prices to consumer prices.

The paper is organized as follows. The next section outlines the event study procedure for common-factor models used for real-time forecasting. Then we discuss the structure of the panels and the forecasting windows and the event-study applications of common-factor models to Swiss inflation.

\section{THE IDENTIFICATION SCHEME}

The identification scheme to analyze announcement effects in macroeconomic models with data-rich environments involves the following steps. The first step generates the projection 
for the variable of interest one day before the release of macroeconomic information. The projections are based on panels that encompass realtime information from financial variables and data releases that are updated on a daily basis. Estimation follows the dynamic common-factor procedure by Forni et al. (2000). The second step reestimates the projections for the variable of interest one day later that include cross-sectional information from the macroeconomic release. The third step constructs the forecast innovation linked to the announcement surprise-that is, the one-day difference in the two projections. The main steps of the estimation procedure are defined using the terminology of MacKinlay (1997).

\section{Defining the Event}

The monthly release of macroeconomic variables is defined as the event with the $k$ th event date $\tau_{k}=(j, t)$ corresponding to day $j$ and month $t$ in calendar time and $k=\{1, \ldots, K\}$. We assume that new information attributed to the event stems from the monthly macroeconomic release. This assumption means that updated panels at the time of the event are not subject to data revisions on days when macroeconomic information is released. Ideally, we focus on macroeconomic releases that are large in the cross section (i.e., the consumer price index [CPI] and its subcomponents) to reduce the influence of measurement error in estimation.

\section{Estimation}

The empirical model relies on data-reduction techniques that can handle real-time panels that are updated daily. We follow the estimation procedures of Forni et al. (2000), Cristadoro et al. (2005), and Altissimo et al. (2001). We provide an informal outline of the estimation procedure, but readers may refer to the individual papers for specific details.

As in Forni et al. (2000) and following their notation, we assume that the factor structure has $N$ variables in the generic panel, $\boldsymbol{x}_{t}=$ $\left(x_{1, t}, x_{2, t}, \ldots, x_{N, t}\right)^{\prime}$, where $x_{1, t}$ is the variable of interest. In most cases, $x_{1, t}$ is either inflation or output. The variables in the panel are first differ- enced when necessary for stationarity purposes. Next, $x_{1, t}$ is assumed to be the sum of two unobservable components: a signal, $x_{1, t}^{*}$, and a component capturing short-run dynamics, seasonality, measurement error, and idiosyncratic shocks, $e_{i, t}$ :

$$
x_{1, t}=x_{1, t}^{*}+e_{1, t} .
$$

The objective of the generalized dynamic factor model of Forni et al. (2000) is to estimate the signal, $x_{1, t}^{*}$, in equation (1) using information from the present and past of the $x$ 's (i.e., a contemporaneous linear combination of the $x$ 's).

More formally, it is assumed that the variables in equation (1), $x_{1, t}$, can be represented as the sum of two stationary, mutually orthogonal, unobserved components. The first component is the common component, $\chi_{i, t}$, which is assumed to capture a high degree of comovement between the variables in the panel, $\boldsymbol{x}_{t}$. The second component is the idiosyncratic component, $\xi_{i, t}$. The common component is defined by $q$ common factors, $u_{h, t}$, that are possibly loaded with different coefficients and (finite) lag structures, say, of order $s$. Formally, Forni et al. (2000) specify $x_{1, t}$ as a generalized dynamic factor model:

$$
x_{i, t}=\chi_{i, t}+\xi_{i, t}=\sum_{h=1}^{q} \sum_{k=0}^{s} b_{i, h, k} u_{h, t-k}+\xi_{i, t},
$$

where $\xi_{i, t}$ is the idiosyncratic component and $\chi_{i, t}=x_{i, t}-\xi_{i, t}$ is the common component.

The estimation procedure as in Cristadoro et al. (2005) involves three steps. The first step estimates the common factors. In particular, the cross spectra for the common component of $\chi_{1, t}$ are estimated following Forni et al. (2000). The second step computes the implied covariance of $\chi_{1, t}$ and the factors by integrating the cross spectra over a specified frequency band. The last step involves performing a linear projection of the common component on the present and the lags of the common factors:

(3) $\hat{\chi}_{1, t}=\operatorname{Proj}\left[\chi_{1, t} \mid u_{h, t-k}, h=\{1, \cdots, q ; k=0, \cdots, s\}\right]$.

To generate the projections at time $t$, we apply the shifting procedure for the covariance matrix by Altissimo et al. (2001; see their Appendix B.4 on filling in incomplete observations for unbal- 
anced panels). ${ }^{2}$ Altissimo et al. (2001) compute values of $\hat{\chi}_{i, t} g$ months ahead by individually shifting each series in $x_{i, t}$ so that the most recent observation aligns $g$ months ahead to form a balanced panel. Afterward the generalized principal component is evaluated for the realigned $x_{i, t}$.

\section{Announcement Surprise Component}

The event study literature frequently uses the term "abnormal returns" for the response of financial variables to an examined event. This is defined as the actual ex post return of the (financial) variable over the event window minus the normal return-the return that would be expected if the event did not take place. Instead of returns, we work with innovations of the projections. Thus, to identify the influence of new information from monthly releases in import prices, a measure of innovations for event date $\tau_{k}=(j, t)$ is needed. This is defined as the one-day difference in the projections of $\hat{\chi}_{1, t}$ around the event (i.e., the release dates). More specifically, $\varepsilon_{1, t}$ is the innovation from the projections for $\hat{\chi}_{1, t \mid P_{j, t}}$ conditional on the daily panel, $P_{j, t}$, before and after the release of the macroeconomic variable on day $j$ in month $t$ :

$$
\hat{\varepsilon}_{1, t}=\hat{\chi}_{1, t \mid P_{j, t}}-\hat{\chi}_{1, t \mid P_{j-1, t}} .
$$

Similarly, the $h$-ahead forecast innovation for $h>0$ is $\hat{\varepsilon}_{1, t+h}=\hat{\chi}_{1, t+h \mid P_{j, t}}-\hat{\chi}_{1, t+h \mid P_{i-1, t}}$. Equation (4) represents the full-day impact from the macroeconomic announcement. ${ }^{3}$

The anticipated component for inflation in equation (4), $\hat{\chi}_{1, t \mid P_{j-1, t}}$, is conditional on a broad range of information. In a similar manner, the anticipated component can be derived for any variable in the panel, $P_{j-1, t}$. This represents an improvement over earlier studies reviewed in MacKinlay (1997) that used survey data or simple regression techniques projected on a handful of variables to generate the anticipated component.

\footnotetext{
2 Giannone, Reichlin, and Small (2008) offer an alternative procedure for forecasts of the common component based on the Kalman filter, which are qualitatively the same.

3 Event studies frequently analyze the immediate impact, which is generally defined as the market response 30 minutes before and 30 minutes after the macroeconomic announcement, rather than the full-day impact.
}

As discussed in Rigobon and Sack (2008), anticipated components using survey data are problematic because of irregular timing and a limited number of surveyed panelists. Rigobon and Sack argue that these problems contaminate the surprise terms and generate a biased impact effect in event studies. They propose an error-in-variables procedure to overcome these problems stemming from survey data. Equation 4 has no such problems.

\section{THE (DAILY) PANELS AND DATA RELEASES}

All economic series used to construct the data panels are from the SNB's data bank. The dataset's construction is intended to replicate the contours of a data-rich environment in which the SNB operates.

\section{The Panels}

Because we are concerned with the problem of how to weigh the most recent information against what we already know at daily intervals, we are interested in economic data that are frequently released, which means working with data with a daily or monthly frequency. Table 1 shows the breakdown of the 434 series into nominal and real variables and their frequency. There are 27 financial variables at the daily frequency and 407 nominal and real variables at the monthly frequency. Quarterly variables such as industrial production or GDP were intentionally excluded to avoid contaminating our estimates with revision errors. ${ }^{4}$

Two types of panels are constructed. The first uses end-of-month data from 1993:05 to 2003:11; we generate our initial forecasts with this panel. After 2003:11:01, we update the panels daily. The starting date 1993:05 is chosen because a large number of series do not go farther back than 1990 and 1993:05 coincides with a major revision in the CPI.

An explicit intention in constructing the dataset was to transform the series as little as possible.

\footnotetext{
4 See Amstad and Fischer (2009a) for a discussion of data revision at the monthly frequency. Also, preliminary estimates revealed that the introduction of the quarterly information from GDP or industrial production did not alter our estimates.
} 


\section{Table 1}

\section{Data and Release Frequencies}

\begin{tabular}{lrr} 
& & Release frequency \\
Data category & Monthly & Daily \\
\cline { 2 - 3 } Nominal & 178 & 254 \\
Prices (CPI total, subcomponents, cores) & 9 & 9 \\
Money & 6 & 11 \\
Financial & 12 & 3 \\
Interest rates & 4 & 4 \\
Exchange rates & 10 & 180 \\
Foreign prices & 8 & \\
Foreign interest rates & & \\
Real & 40 & 83 \\
Survey & 14 & 27 \\
External trade & 16 & \\
Labor & 8 & \\
Demand & 19 & \\
Foreign industrial production & 407 & \\
Foreign labor market & & \\
Total & & \\
\end{tabular}

First, we undertake no seasonal filtering because of its reliance on future information. Amstad and Fischer (2009a) demonstrate that seasonal adjustment can be treated through band-pass filtering. The absence of seasonal revisions allows better interpretation of the forecast innovations.

Several data transformations, however, were necessary at the initial stages of estimation. The series were filtered in the following manner. First, logarithms were taken for nonnegative series that were not in rates or in percentage units to account for possible heteroskedasticity. Second, the series were first-differenced, if necessary, to account for stochastic trends. Third, the series were taken in deviation from the mean and divided by their standard deviation to remove scalar effects.

\section{Clustered Data Releases}

Figure 1 provides an example of the clustering of macroeconomic releases for December 2003. The number of data releases for a particular day is listed on the vertical axis with the calendar dates denoted on the horizontal axis. The releases are divided into nominal (shaded bars) and real variables (open bars). Of interest are the clusterings on December 2 and 19. The first spike stems from CPI releases and their subcomponents, whereas the second is the result of the release of trade volumes across sectors.

\section{APPLICATIONS TO SWISS INFLATION FORECASTS}

This section presents three empirical applications of analyzing the impact of macroeconomic announcement effects on Swiss CPI inflation. ${ }^{5}$ The case studies were chosen to reflect the view that the event study framework for common-factor

5 The empirical model is defined in Amstad and Fischer (2009a). The same paper provides forecasting properties for a model with 12 static factors and 2 dynamic factors. Inflation is annualized and uses a band-pass filter at $2 \pi / 12$ to remove seasonality. This is also the same dataset and estimation procedure used to estimate the SNB's monthly measure of core inflation, called dynamic factor inflation. See page O15 of the SNB's Monthly Statistical Bulletin. 


\section{Figure 1}

\section{Nominal and Real Data Releases for December 2003}

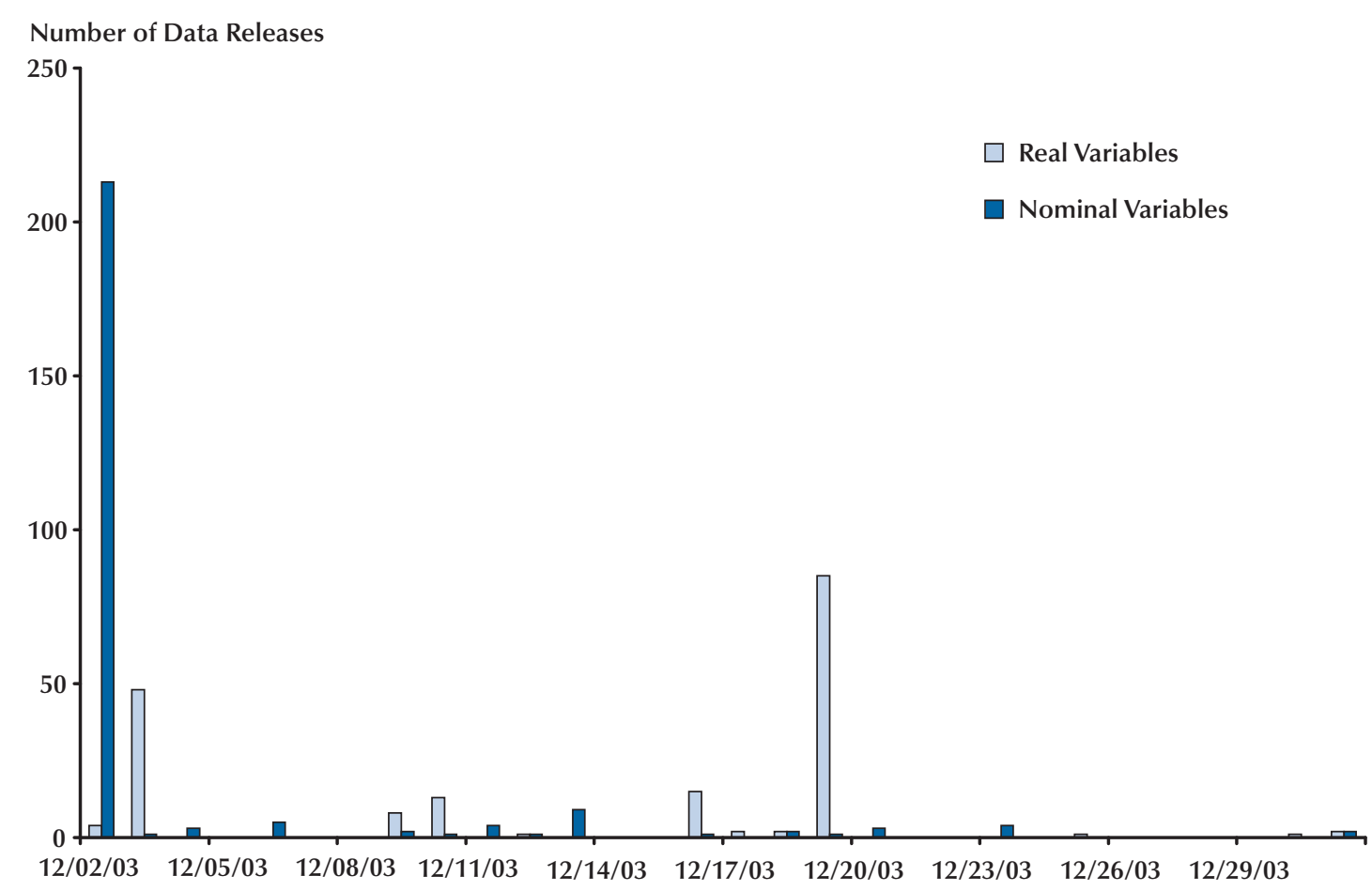

models has broad applications. The first exercise considers forecast innovations generated on days when the SNB announced its target range for the 3-month London Interbank Offering Rate (LIBOR) in 2004. In particular, we are interested in how financial variables respond to SNB communication and its impact on the inflation forecast. The second application asks whether forecast innovations generated by data releases of real and nominal variables to CPI inflation are synchronized. In other words, do the data releases from real and nominal variables influence the inflation forecast in a similar manner? The last application examines whether forecast innovations generated by import price releases influence CPI inflation. In particular, we want to know whether the impact is similar in magnitude to pass-through ratios estimated in other studies that use traditional time-series methods.

\section{SNB Announcement Surprises in 2004}

The SNB defines a target range of 100 basis points for the 3-month LIBOR as its operating target. To steer the LIBOR within the target range, the SNB sets the 1-week repurchase (repo) rate. Four times per year on scheduled dates, the SNB releases a policy statement in which it announces a change or no change in the target range. ${ }^{6}$ In 2004 , the announcement dates were March 18, June 17, September 16, and December 16. We use these four policy dates to generate the SNB announcement surprises. The SNB "announcement surprise" is defined as the one-day difference in the inflation forecast conditional on postrelease information minus the inflation forecast conditional on prerelease information. The difference in this information set captures only information from

6 Outside these prearranged dates, the SNB reserves the right to change the target range. 
(daily) financial variables and their reaction to the policy statement (i.e., no releases of macroeconomic data were made public on the four SNB policy dates). These differences in the panels pertain to daily updates in the 27 financial variables in our panel.

Figure 2 plots innovations of 24-month-ahead inflation forecasts at the time of the four SNB announcement dates. In June and September the SNB's board of directors raised the target range by 25 basis points, whereas in March and in December the target range was left unchanged. The responses to the SNB announcement surprises differ considerably. For the March release, there is no change in the forecast. However, for the dates when the SNB raised its target range, we observe a strong response in the inflation forecast but in opposite directions. Contractionary behavior is observed for the June rate hike and expansionary behavior for the September rate hike. For the last announcement surprise in December, we observe a weak but expansionary response to the "no-change" decision. Although the forecast innovations on days when changes to the target range are larger than on days with no changes to the target range, we do not find them to be statistically significant compared with forecast innovations on SNB days in the years between 2000 and 2003. Next, we focus on the direction of the forecast innovation.

How do we explain the differing reactions to the change and no-change decisions in the target range? The release dates that signal a change in the target range account for larger reactions in the inflation forecast. The stronger forecast response on SNB days with a change in the target range rests on the fact that many financial contracts in Switzerland (i.e., automobile leases, home and commercial property loans) are tied to the 3-month LIBOR. To determine the innovation's direction, it is necessary to control for what the markets had anticipated. As in Hamilton and Jorda (2002), one possible method (aside from the projection one day before the SNB announcement day) is to use a spread of the SNB's policy rates: the 3-month LIBOR rate minus the repo rate. This interest rate spread is plotted in Figure 3 along with the midpoint in the SNB's target range for the 3-month LIBOR. ${ }^{7}$ The interest rate spread shows that the market anticipated the rate hikes in June and September; the spreads widen. For the no-change decisions, the spreads do not change in March and widen slightly before the December policy release.

To understand the postrelease estimate, we need to examine what happens to the spread the day after the SNB policy statements are released. For the March release, the spread does not change between the preforecast and postforecast. This is consistent with the March response of no reaction to the SNB announcement surprises. For the June release, the change in the spread is 0.01 , whereas for the September release it is -0.14 . In the latter case, the SNB did not raise the repo rates high enough to move the 3-month LIBOR to the midpoint of the target range. In other words, the short end of the yield curve was steeper than was anticipated by the market. This led to a rise in the postrelease estimate of inflation. The response to the December release of no change in the target range is similar to the response for the September release. Although the reaction for September is small, the change in the spread for the postrelease and prerelease dates of -0.04 is consistent with the innovation's direction.

\section{Are Real and Nominal Forecast Innovations Synchronized?}

Next, we test whether forecast innovations from data releases of real and nominal variables are synchronized. We generate the forecast innovations from the monthly trade releases (i.e., "real innovations") and the forecast innovation from the monthly CPI releases (i.e., "nominal innovations"). A priori, we do not expect the two types of forecast innovations to be similar. First, the size and dynamics of the individual forecast innovations can differ from month to month. Second, the comovement of real and nominal innovations should not be restricted to be the same for each month. In related empirical studies on the procyclicality of prices in the long run, Backus and Kehoe (1992), Ravn and Sola (1995), and Smith (1992) find that the cyclical properties of prices and output are not stable.

\footnotetext{
7 The repo rate is either the 1-week or the 2-week repo rate; in most
} cases, it is the former. See Dueker and Fischer (2005). 
Figure 2

Forecast Innovations of SNB Announcements to the Target Range

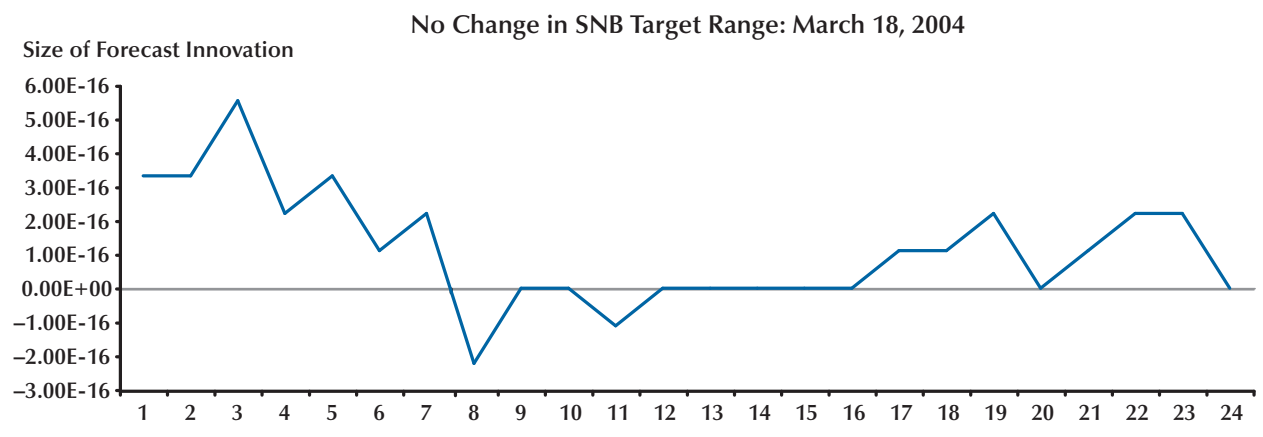

Size of Forecast Innovation

25-Basis-Point Raise in SNB Target Range: June 16, 2004

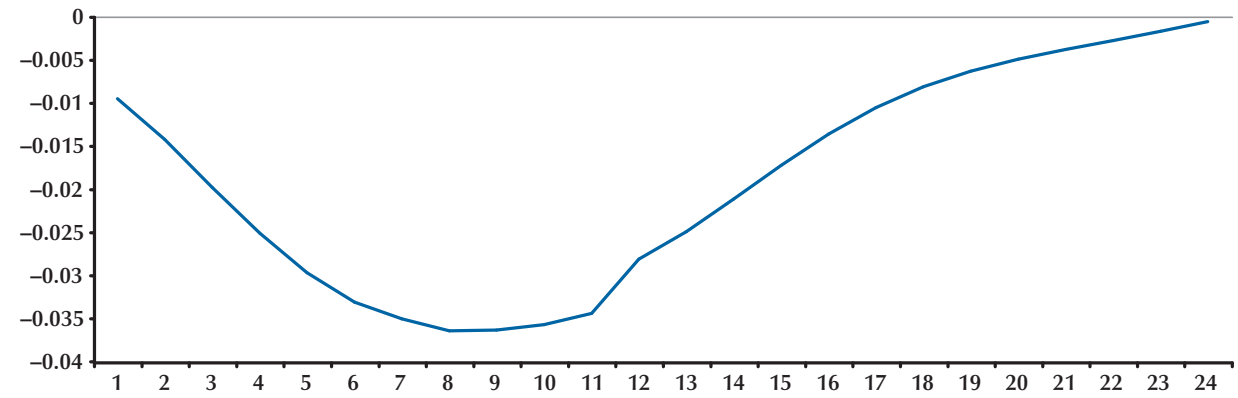

25-Basis-Point Raise in SNB Target Range: September 16, 2004

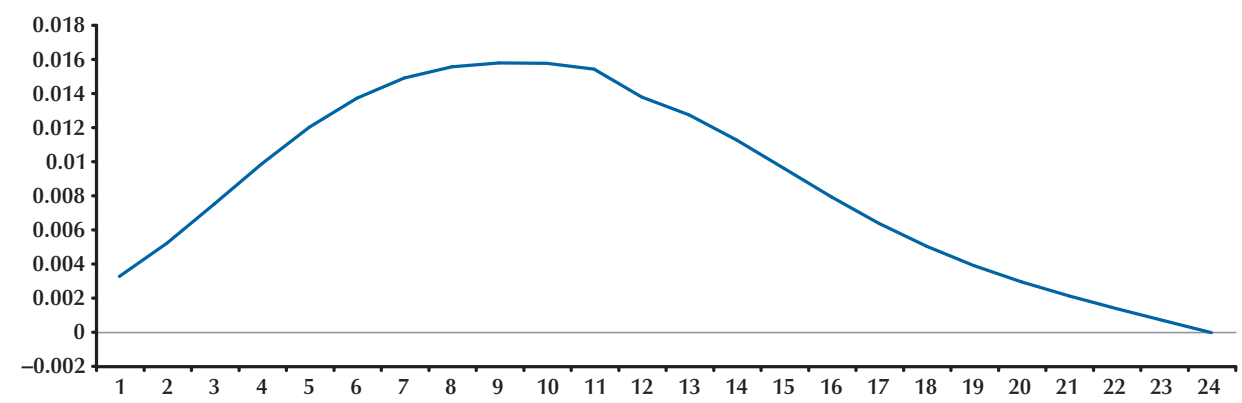

Size of Forecast Innovation No Change in SNB Target Range: December 16, 2004

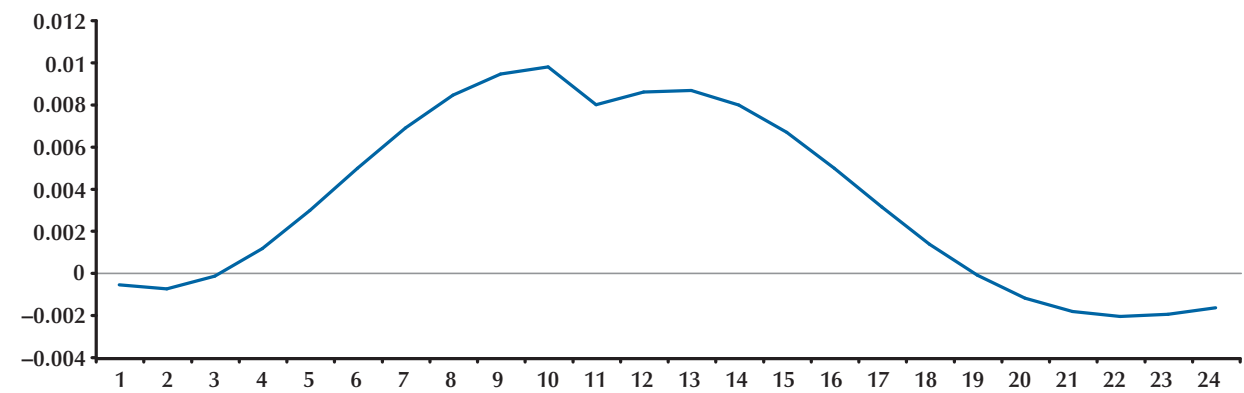




\section{Figure 3}

\section{SNB Policy Rates in 2004}

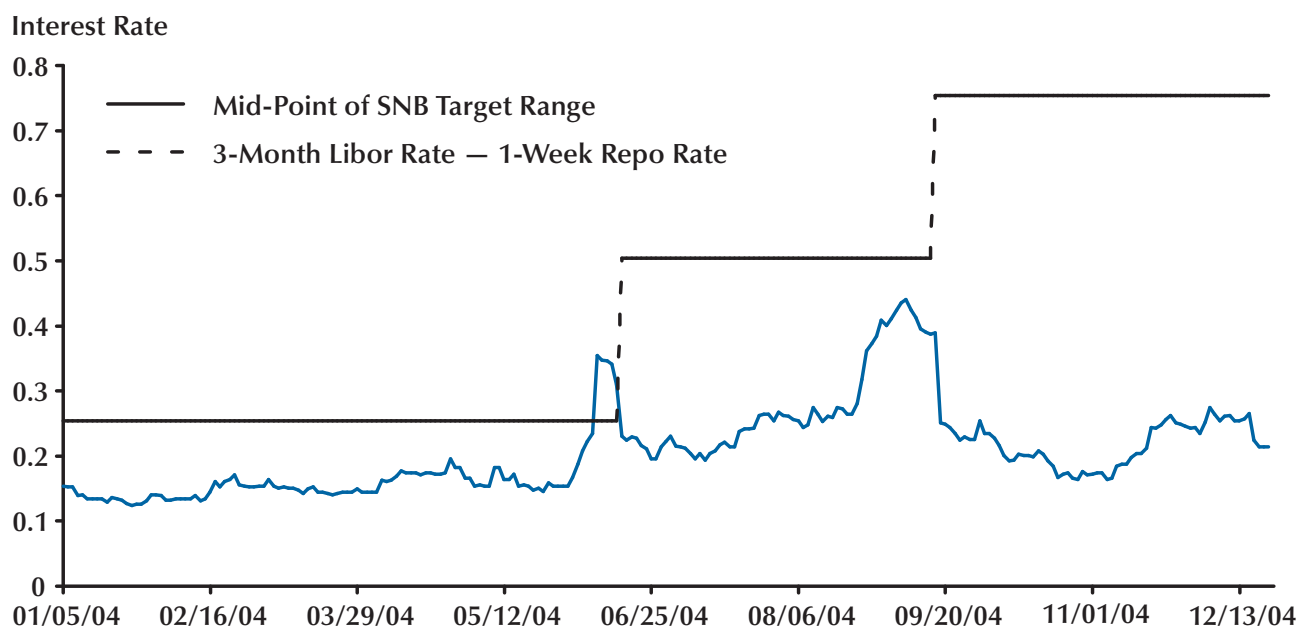

SOURCE: Dueker and Fischer (2005).

\section{Table 2}

\section{Synchronization of Forecast Innovations from Nominal and Real Variable Releases}

\begin{tabular}{lcccccc} 
Forecast innovations & $\begin{array}{c}\text { November } \\
\mathbf{2 0 0 4}\end{array}$ & $\begin{array}{c}\text { October } \\
\mathbf{2 0 0 4}\end{array}$ & $\begin{array}{c}\text { September } \\
\mathbf{2 0 0 4}\end{array}$ & $\begin{array}{c}\text { August } \\
\mathbf{2 0 0 4}\end{array}$ & $\begin{array}{c}\text { July } \\
\mathbf{2 0 0 4}\end{array}$ & $\begin{array}{c}\text { June } \\
\mathbf{2 0 0 4}\end{array}$ \\
\hline$\varepsilon_{\pi, t+h \mid j, t}^{n} \varepsilon_{\pi, t+h \mid k, t}^{r}$ & 0.174 & 0.348 & 0.130 & 0.348 & 0.826 & 0.565 \\
$\varepsilon_{\pi, t+h \mid j, t}^{n} \varepsilon_{\pi, t+h \mid j-1, t}^{n}$ & 0.522 & 0.522 & 0.870 & 0.822 & 0.391 & 0.261 \\
$\varepsilon_{\pi, t+h \mid k, t}^{r}, \varepsilon_{\pi, t+h \mid k-1, t}^{r}$ & 0.610 & 0.740 & 0.565 & 0.478 & 0.652 & 0.434
\end{tabular}

NOTE: The forecast innovations generated by real and nominal variable releases are denoted by $\varepsilon_{\pi, t+h \mid k, t}^{r}$ and $\varepsilon_{\pi, t+h \mid j, t}^{n}$. The index for concordance by Harding and Pagan (2002) lies between 0 (countercyclical) and 1 (procyclical). The index is calculated for the months June through November 2004.

To test whether the two types of forecast innovations are synchronous, we calculate the concordance index of Harding and Pagan (2002). The application of the index examines whether the comovement of real and nominal innovations can be quantified by the fraction that both series are simultaneously in the same state of expansion $\left(S_{t}=1\right)$ or contraction $\left(S_{t}=0\right)$ with the index,

$$
I_{1,2}=\frac{\sum_{t=1}^{24} S_{1, t} S_{2, t}+\left(1-S_{1, t}\right)\left(1-S_{1, t}\right)}{24},
$$

measuring the degree of concordance between series 1 and 2, which are $\varepsilon_{\pi, t+h \mid k, t}^{r}$ and $\varepsilon_{\pi, t+h \mid j, t}^{n}$ in our case. ${ }^{8}$

The concordance index can be used to determine whether nominal and real innovations to inflation are procyclical or countercyclical. If they are exactly procyclical, then the index is unity, whereas a zero value denotes evidence of countercyclical behavior. Table 2 presents the

8 The concordance index has similar properties as the Cowles-Jones test used for testing an i.i.d. random walk process. 
Figure 4

\section{Exchange Rate Pass Through}
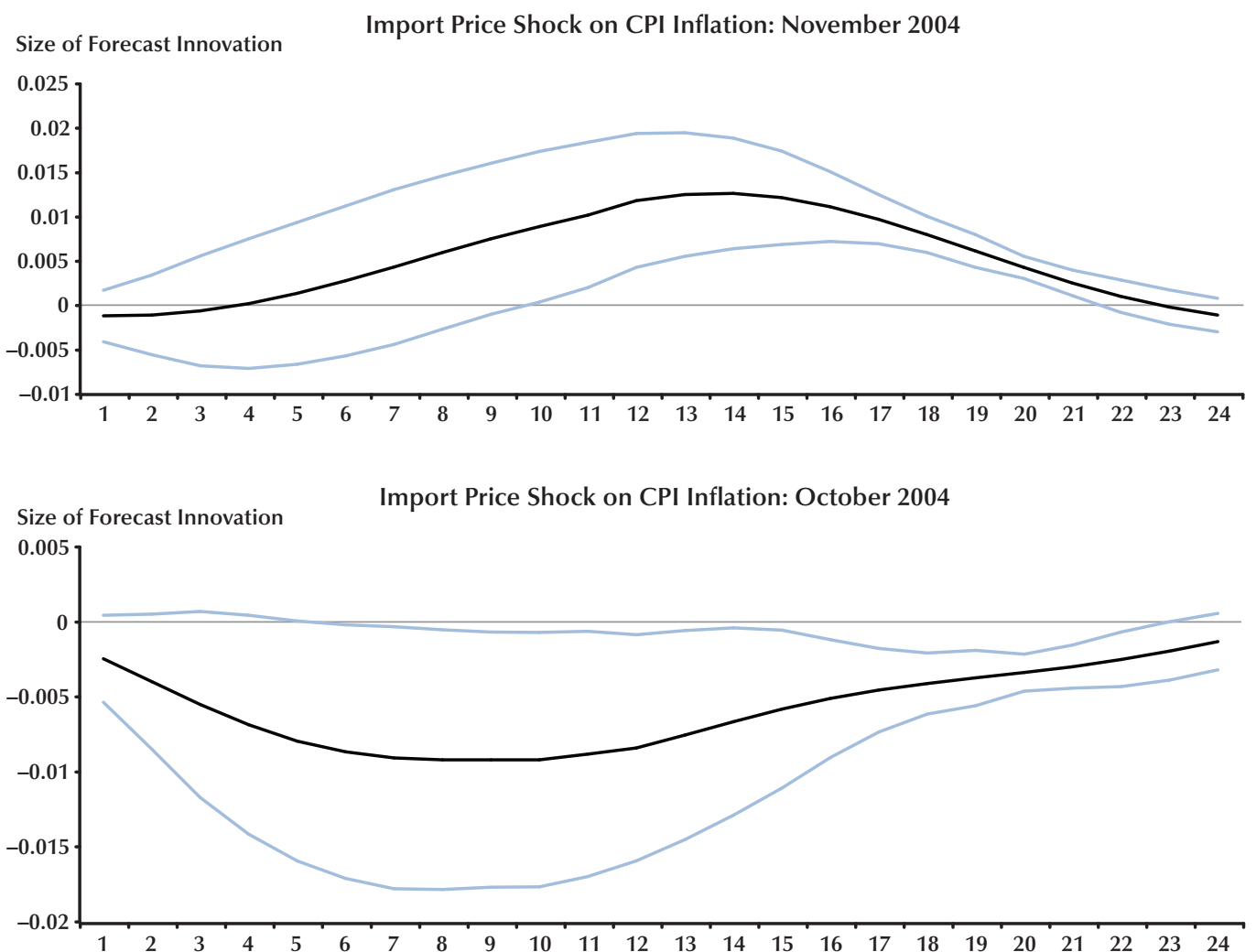

Size of Forecast Innovation

Import Price Shock on CPI Inflation: September 2004

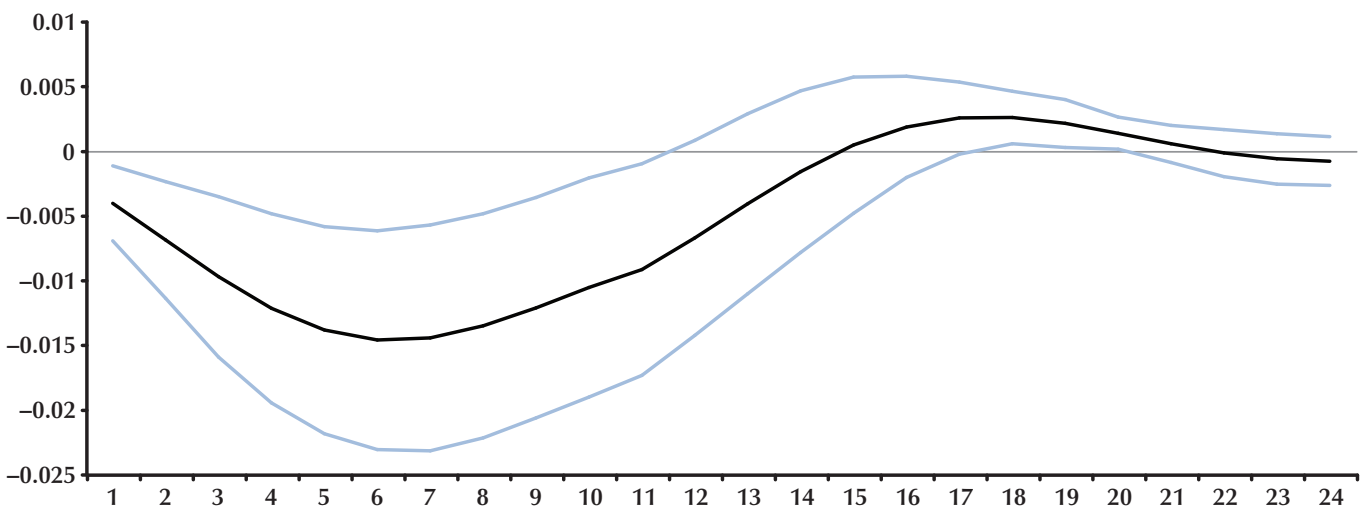


degree of concordance between $\varepsilon_{\pi, t+h \mid k, t}^{r}$ and $\varepsilon_{\pi, t+h \mid j, t}^{n}$ for June to November 2004. In the first row of the table, the index values for $\varepsilon_{\pi, t+h \mid k, t}^{r}$ and $\varepsilon_{\pi, t+h \mid j, t}^{n}$ show that the innovations behaved in a procyclical manner in June and July, but the real and nominal innovations to inflation behaved in a countercyclical manner from August through November. In the second and the third rows of the table, information on the persistence of the innovations is given by constructing the index for $\varepsilon_{\pi, t+h \mid j, t}^{n}$ and $\varepsilon_{\pi, t+h \mid j-1, t}^{n}$ and $\varepsilon_{\pi, t+h \mid k, t}^{r}$ and $\varepsilon_{\pi, t+h \mid k-1, t}^{r}$. Here, the evidence shows that the likelihood of the two types of forecast innovations behaving in the same manner (as in the previous month) is stronger for real innovations than for nominal innovations to inflation. In other words, the forecast innovations from real data releases demonstrate a higher level of persistence than do forecast innovations from nominal data releases.

\section{Do Inflation Forecasts Respond to Releases in Import Prices?}

The response of CPI inflation forecasts to import price releases should be informative about the pass through from import prices to consumer prices. ${ }^{9}$ In our setup, the forecast innovation around the import price release is defined as the difference in the 24-month-ahead forecasts in CPI inflation based on the daily panel that includes the postrelease information from import prices and the previous day's panel that entails information from the prerelease.

Figure 4 shows the response of CPI inflation to new information from import price releases for November, October, and September 2004. A onestandard-deviation band, based on past innovations since December 2003, is depicted around the forecast's response. The evidence indicates that the pass through under this measure is small. In November and October, the innovations of the import prices were slightly negative for the first 15 months and zero thereafter. The response for September was stronger; again the effect of import prices is absorbed within 18 months.

The finding that the Swiss pass through is

\footnotetext{
9 This section relies heavily on Amstad and Fischer (2009b).
}

weak in 2004:Q4 does not contradict the crosscountry evidence by Campa and Goldberg (2005), Gagnon and Ihrig (2004), and McCarthy (2000). These studies find that the pass through for Swiss prices is surprisingly small compared with the empirical evidence for other small open economies.

\section{CONCLUSION}

Understanding the influence of real-time information on inflation forecasts is vital for policymakers. The proposed forecasting framework based on the common-factor procedure with daily updated panels is a step in this direction. As in event studies that focus on the response of high-frequency financial data to new information around a narrow event window, the identification scheme herein relies on the recognition that macroeconomic announcement effects can also be interpreted as a forecast innovation with a oneday event window. The case studies for Swiss inflation demonstrate that the event study framework for common-factor models is flexible to handle numerous applications in real time.

\section{REFERENCES}

Altissimo, Filippo; Bassanetti, Antonio; Cristadoro, Riccardo; Forni, Mario; Hallin, Marc; Lippi, Marco; Reichlin, Lucrezia and Veronese, Giovanni.

"EuroCOIN: A Real Time Coincident Indicator of the Euro Area Business Cycle.” CEPR Discussion Paper No. 3108, Centre for Economic Policy Research, 2001; www.cepr.org/pubs/new-dps/dplist.asp?dpno=3108.

Altissimo, Filippo; Cristadoro, Riccardo; Forni, Mario; Lippi, Marco and Veronese, Giovanni. "New Eurocoin: Tracking Economic Growth in Real Time." Banca d' Italia, Temi di discussionedel Servizio Studi No. 631, Bank of Italy, June 2007; www.bancaditalia.it/pubblicazioni/econo/temidi/ td07/td631_07/td631/en_tema_631.pdf.

Amstad, Marlene and Fischer, Andreas M. "Are Weekly Inflation Forecasts Informative?" Oxford Bulletin of Economics and Statistics, April 2009a, 71(2), pp. 236-52. 


\section{Amstad and Fischer}

Amstad, Marlene and Fischer, Andreas M. "Monthly Pass-Through Ratios." Globalization and Monetary Policy Institute Working Paper No. 26, Federal Reserve Bank of Dallas, January 2009b; www.dallasfed.org/institute/wpapers/2009/0026.pdf.

Backus, David K. and Kehoe, Patrick J. "International Evidence on the Historical Properties of Business Cycles." American Economic Review, September 2002, 82(4), pp. 864-88.

Blinder, Alan S.; Ehrmann, Michael; Fratzcher, Marcel; De Haan, Jakob and Jansen, David-Jan. "Central Bank Communication and Monetary Policy: A Survey of Theory and Evidence." Journal of Economic Literature, December 2008, 46(4), pp. 910-45.

Campa, Jose M. and Goldberg, Linda S. "Exchange Rate Pass-Through into Import Prices.” Review of Economics and Statistics, November 2005, 87(4), pp. 679-90.

Cristadora, Riccardo; Forni, Mario; Reichlin, Lucrezia and Veronese, Giovanni. "A Core Inflation Indicator for the Euro Area." Journal of Money, Credit, and Banking, June 2005, 37(3), pp. 539-60.

Dueker, Michael J. and Fischer, Andreas M. "Open Mouth Operations: A Swiss Case Study.” Federal Reserve Bank of St. Louis Monetary Trends, January 2005; http://research.stlouisfed.org/publications/ mt/20050101/cover.pdf.

Evans, Martin D.D. "Where Are We Now? Real-Time Estimates of the Macro Economy." International Journal of Central Banking, September 2005, 1, pp. 127-75.

Forni, Mario; Hallin, Marc; Lippi, Marco and Reichlin, Lucrezia. "The Generalized Dynamic-Factor Model: Identification and Estimation." Review of Economics and Statistics, 2000, 82(4), pp. 540-54.

Forni, Mario; Hallin, Marc; Lippi, Marco and Reichlin, Lucrezia. "Do Financial Variables Help Inflation and Real Activity in the Euro Area?" Journal of Monetary Economics, 2001, 50(6), pp. 1243-55.
Gagnon, Joseph E. and Ihrig, Jane. "Monetary Policy and Exchange Rate Pass-Through." International Journal of Finance and Economics, 2004, 9(4), pp. 315-38.

Giannone, Domenico; Reichlin, Lucrezia and Small, David. "Nowcasting: The Real-Time Informational Content of Macroeconomic Data." Journal of Monetary Economics, May 2008, 55(4), pp. 665-76.

Hamilton, James D. and Jorda, Oscar. "A Model for the Federal Funds Rate Target." Journal of Political Economy, October 2002, 110(5), pp. 1135-67.

Harding, Don and Pagan, Adrian. "Dissecting the Cycle: A Methodological Investigation." Journal of Monetary Economics, March 2002, 49(2), pp. 365-81.

MacKinlay, A. Craig. "Event Studies in Economics and Finance." Journal of Economic Literature, 1997, 35(1), pp. 13-39.

McCarthy, Jonathan. "Pass-Through of Exchange Rates and Import Prices to Domestic Inflation in Some Industrialized Economies." Staff Report No. 111, Federal Reserve Bank of New York, September 2000; www.ny.frb.org/research/staff_reports/sr111.pdf.

Ravn, Morten O. and Sola, Martin. "Stylized Facts and Regime Changes: Are Prices Procyclical?” Journal of Monetary Economics, December 1995, 36(1), pp. 497-526.

Rigobon, Robert and Sack, Brian. "Noisy Macroeconomic Announcements, Monetary Policy, and Asset Prices," in John Campbell, ed., Asset Prices and Monetary Policy (NBER). Chap. 8. Chicago: University of Chicago Press, 2008, pp. 335-70.

Smith, R. Todd. "The Cyclical Behavior of Prices." Journal of Money, Credit, and Banking, November 1992, 24(4), pp. 413-30.

Stock, James H. and Watson, Mark W. "Macroeconomic Forecasting Using Diffusion Indexes." Journal of Business and Economic Statistics, April 2002, 20(2), pp. 147-61. 